Short Communication

\title{
Genetics of the timing of vegetative phase transition in a maize
} population

P. Revilla ${ }^{12}$, R.A. Malvar ${ }^{1}$, A. Butrón ${ }^{1}$, W.F. Tracy ${ }^{3}$, B.G. Abedon ${ }^{3}$, and A. Ordás ${ }^{1}$

${ }^{1}$ Misión Biológica de Galicia, CSIC, Apartado 28, 36080 Pontevedra, Spain. ${ }^{2}$ Corresponding author, E-mail: previlla@mbg.cesga.es. ${ }^{3}$ Department of Agronomy, University of Wisconsin-Madison, Madison, WI 53706.

$\underline{\text { With } 1 \text { table }}$

$\underline{\text { Received February 28, } 2003}$

\author{
Abstract \\ Variability for the timing of transition from juvenile to adult vegetative phases \\ in maize ( $\underline{\text { Zea mays }}$ L.) is assumed to be genetically regulated and has been \\ associated with disease and pest resistance. The objective of this work was to \\ estimate the genetic variances of vegetative phase transition and its correlation \\ with yield and its components. Full-sib and half-sib families were developed in \\ a maize synthetic, following the Design I mating system. Progenies were \\ evaluated in randomized complete block design with sets within replications in \\ northwestern Spain for two years. Phase transition-related traits showed \\ significant additive variance, no interaction with environment, and high \\ heritability (above 65\%). Correlation coefficients indicate that selection for \\ delayed transition should not affect yield or its components. Therefore,
}


selection for delaying phase transition in order to increase disease and pest resistance could be used without expecting serious detrimental effects on yield.

Key words: $\underline{\text { Zea mays, }}$ maize, genetic variance components, phase transition, additive genetic correlation.

Maize vegetative development is divided into juvenile and adult phases based on differences in leaf and stem anatomy and physiology, such as the presence of epicuticular wax in juvenile leaves (Poethig 1990). Earlier vegetative phase transition is associated with resistance to maize diseases and pests (Abedon and Tracy 1996).

Abedon et al. (1996) found that general combining ability was more important than specific combining ability for phase transition-related traits. Abedon and Tracy (1998) observed that these traits were unaffected by inbreeding depression and Revilla et al. (2002) obtained significant response to recurrent selection. However, the genetic variances and heritabilities of phase transition-related traits have not been estimated directly. The objective of this work was to estimate the genetic variances of vegetative phase transition and its correlation with yield and its components.

Experimental design: In the maize synthetic 'EPS5' (Revilla et al., 2002), 144 full-sib and 48 half-sib families were developed using the Design I mating system. A randomized complete block design with two replications and twelve 
sets within replication was used. Each set consisted of four half-sib families and 12 full-sib families, according to Malvar et al. (1996). Plots consisted of two rows with 10 plants per row with a density of approximately 60000 plants $\mathrm{ha}^{-1}$. The experiment was grown in 1996 and 1997 at Pontevedra (at sea level) in northwestern Spain. During the maize growing season (May to October) mean monthly temperatures varied from 11.2 to $20.2^{\circ} \mathrm{C}$ in 1996 and from 15.5 to $20.8^{\circ} \mathrm{C}$ in 1997 . Total rainfall from May to October was $574.5 \mathrm{~mm}$ in 1996 , with a monthly variation from 18.7 to $196.5 \mathrm{~mm}$; while in 1997 total rainfall was $722.1 \mathrm{~mm}$, with a monthly variation from 4.5 to $268.5 \mathrm{~mm}$.

Data analyses: The following traits were analysed: days to 50\% silking, number of ears per plant, ear length (cm), ear-row number, 100-kernel weight (g), kernel moisture content at harvest $\left(\mathrm{g} \mathrm{kg}^{-1}\right)$, grain yield $\left(\mathrm{kg} \mathrm{ha}^{-1}\right.$ at a moisture content of $140 \mathrm{~g} \mathrm{~kg}^{-1}$, calculated on a plot basis), number of leaves with epicuticular wax, and number of leaves without epicuticular wax below the main ear. Individual and combined analyses of variance across years were calculated. The effects of all sources of variation were considered as random. Estimates of variance components were computed by REML using the VARCOMP procedure of the SAS program (SAS 2000). Narrow-sense heritabilities, confidence intervals, and additive genetic correlations between pairs of traits were computed. Statistical analyses were made following Hallauer and Miranda (1988) and Malvar et al. (1996). 
Results and Discussion: The analyses of variance for each year showed that none of the estimates of dominance variance was significant, while all estimates of additive variances were significant (data not shown). In the combined analyses of variance, additive variance was significant for row number, kernel moisture, number of leaves with epicuticular wax, and leaves without epicuticular wax below the ear (Table 1). The additive $\times$ environment interaction variance was significant for ear length, ear-row number, kernel weight, and yield. Neither the dominance variance nor the dominance $\times$ environment interaction variance were significant for any trait. Heritabilities $\left(h^{2}\right)$ were below 0.5 , except for kernel moisture, number of leaves with epicuticular wax and leaves without epicuticular wax below the ear (Table 1). The additive correlation between number of leaves with epicuticular wax and number of adult leaves (without epicuticular wax) below the ear was moderate and negative(-0.55). Number of leaves with epicuticular wax had a significant positive correlation with pollen date (0.76), silking date (0.54), plant height (0.37), ear length (0.52), and kernel moisture (0.37). Finally, adult leaves (without epicuticular wax) below the ear had significant negative correlation with early vigor (-0.39), plant height (-0.62), and ear length (-0.33). All these figures were significant at $\mathrm{P}=0.05$.

The significance of additive variance and the lack of significant dominance variance for phase transition-related traits agree with the results reported by Abedon et al. (1996) who found that for leaves with juvenile wax and other phase transition-related traits general combining ability was 
significant, and neither specific combining ability nor interactions with environment were significant. Also, Abedon and Tracy (1998) suggested that additive effects were more important than dominance effects on the genetic variability of phase transition. Besides, heritabilities of phase transition-related traits were moderately high.

Selection for delaying phase transition, thus increasing the number of leaves with epicuticular wax, could delay flowering, and increase plant and ear height, and kernel moisture. On the contrary, enlarging the number of adult leaves (without epicuticular wax) below the ear, could reduce early vigor, and plant and ear height. No significant effects or selection on yield or its components should be expected. Accordingly, Revilla et al. (2002) concluded that selection response was significant and more efficient for late phase transition than for early phase transition, with no correlated responses on any agronomic trait. Thus, selection for delaying phase transition should be efficient and no significant detrimental correlated response on yield and its components must be expected.

Further research is needed in order to find out if selection for delaying phase transition could be of any help on breeding programs for resistance to diseases and pests.

\section{References}

Abedon, B.G., P. Revilla, and W.F. Tracy, 1996: Vegetative phase change in sweet corn populations: genetics and relationships with agronomic 
traits (Vegetative phase change in open-pollinated sweet corn). Maydica $41,77-82$.

Abedon, B.G., and W.F. Tracy, 1996: $\underline{\text { Corngrass1 }}$ of maize (Zea mays L.) delays development of adult plant resistance to common rust (ucinia

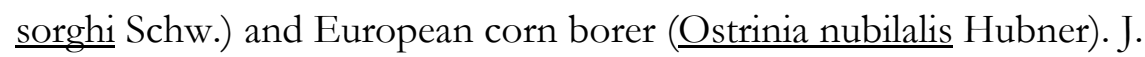
Hered. 87, 219-223.

Abedon, B.G., and W.F. Tracy, 1998: Inbreeding and the timing of vegetative phase change in maize ( $\underline{\text { Zea mays }}$ L.). Maydica 43, 143-146.

Hallauer, A.R., and J.B. Miranda Fo. 1988. Quantitative genetics in maize breeding. $2^{\text {nd }}$. ed. Iowa State Univ. Press. Ames, Iowa, USA.

Malvar, R.A., A. Ordás, P. Revilla, and M.E. Cartea. 1996. Estimates of genetic variances in two Spanish populations of maize. Crop Sci. 36, 291-295.

Poethig, R.S, 1990: Phase change and the regulation of shoot morphogenesis in plants. Science 250, 923-930.

Revilla, P., R.A. Malvar, A. Butrón, W.F. Tracy, B.G. Abedon, and A. Ordás. 2002. Response to selection for the timing of vegetative phase transition in a maize population. Crop Sci. $42,1471-1474$.

SAS, 2000: The SAS System. SAS OnlineDoc.HTML Format. Version eight. SAS Institute, Cary, North Carolina. 
Table 1. Estimates of additive $\left(\boldsymbol{\sigma}^{2} \mathrm{~A}\right)$, dominance $\left(\boldsymbol{\sigma}^{2} \mathrm{D}\right)$, additive $\times$ environments $\left(\boldsymbol{\sigma}^{2} \mathrm{AE}\right)$ and dominance $\times$ environments $\left(\boldsymbol{\sigma}^{2} \mathrm{DE}\right)$ variance, and heritability $\left(\mathrm{h}^{2}\right)$ with $95 \%$ confidence interval (CI) in the maize synthetic 'EPS5'.

\begin{tabular}{|c|c|c|c|c|c|c|}
\hline Trait & $\sigma^{2} \mathrm{~A}$ & $\sigma^{2} \mathrm{D}$ & $\sigma^{2} \mathrm{AE}$ & $\sigma^{2} \mathrm{DE}$ & $h^{2}(\%)$ & $\mathrm{CI}(\%)$ \\
\hline Ear length $(\mathrm{cm})$ & $0.31 \pm 0.70$ & $1.28 \pm 1.37$ & $1.36 * \pm 0.75$ & $0.00 \pm 0.75$ & 10 & $0-51$ \\
\hline Ear-row number (no.) & $0.78^{*} \pm 0.41$ & $0.55 \pm 0.72$ & $0.41 * \pm 0.20$ & $0.00 \pm 0.42$ & 46 & $2-69$ \\
\hline Kernel weight (g) & $2.76 \pm 2.51$ & $4.45 \pm 4.43$ & $4.53 * \pm 2.00$ & $0.00 \pm 2.00$ & 24 & $0-56$ \\
\hline Kernel moisture $\left(\mathrm{g} \mathrm{kg}^{-1}\right)$ & $1.54^{*} \pm 0.71$ & $0.00 \pm 1.68$ & $0.14 \pm 0.48$ & $0.88 \pm 1.25$ & 53 & $10-75$ \\
\hline Yield $\left(\mathrm{kg} \mathrm{ha}^{-1}\right)^{\xi}$ & $0 \pm 0$ & $148 \pm 119$ & $314 * \pm 126$ & $0 \pm 295$ & 0 & $0-41$ \\
\hline Leaves with epic. wax & $0.57 * \pm 0.18$ & $0.00 \pm 0.27$ & $0.03 \pm 0.04$ & $0.00 \pm 0.04$ & 69 & $44-82$ \\
\hline Leaves without wax below ear & $0.47 * \pm 0.17$ & $0.09 \pm 0.30$ & $0.05 \pm 0.06$ & $0.12 \pm 0.15$ & 66 & $38-80$ \\
\hline
\end{tabular}

* Estimate significantly different from zero, based on an F-test $(\mathrm{P}<0.05)$.

${ }^{\xi}$ Estimates of $\sigma^{2}{ }_{\mathrm{D}} \sigma^{2} \mathrm{AE}$ and $\sigma^{2} \mathrm{DE}$ and their standard error are divided by $10^{-3}$. 